\title{
OH Airglow and Equatorial Variations Observed by ISUAL Instrument on Board the FORMOSAT 2 Satellite
}

\author{
Jan-Bai Nee ${ }^{1, *}$, Shang-Da Tsai ${ }^{1}$, Ting-Hung Peng ${ }^{1}$, Rue-Ron Hsu ${ }^{2}$, Alfred Bin-Chi Chen ${ }^{2}$, \\ Shengpan Zhang ${ }^{3}$, Tai-Yin Huang ${ }^{4}$, Panthalingal K. Rajesh ${ }^{5}$, Jann-Yenq Liu ${ }^{5}$, \\ Harold U. Frey ${ }^{6}$, and Steven B. Mende ${ }^{6}$ \\ ${ }^{1}$ Department of Physics, National Central University, Jhongli, Taiwan, ROC \\ ${ }^{2}$ Department of Physics, National Cheng Kung University, Tainan, Taiwan, ROC \\ ${ }^{3}$ Center for Research in Earth and Space Science, York University, Toronto, Canada \\ ${ }^{4}$ Penn State Lehigh Valley, Center Valley, Pennsylvania, USA \\ ${ }^{5}$ Institute of Space Science, National Central University, Jhongli, Taiwan, ROC \\ ${ }^{6}$ Space Science Laboratory, University of California, Berkeley, California, USA
}

Received 18 December 2009, accepted 12 March 2010

\begin{abstract}
OH airglow observed by the ISUAL (Imager of Sprites and Upper Atmospheric Lightning) instrument on board the FORMOSAT 2 satellite is reported in this paper. The satellite is sun-synchronous and it returns to the same orbit at the same local time daily. By using this property, we can study the upper atmosphere in detail. With a CCD camera, ISUAL has measured the emission layers of $\mathrm{OH}$ Meinel band at $630 \mathrm{~nm}$ for several two-week periods in 2004 and 2007 in equatorial regions. ISUAL images are snapshots of the atmosphere $250 \mathrm{~km}$ (height) $\times 1200 \mathrm{~km}$ (horizontal distance). These images of $\mathrm{OH}$ airglow are analyzed to derive its peak height and latitudinal variations. ISUAL observation is unique in its capability of continuous observation of the upper atmosphere as the satellite travels from south to north along a specific orbit. However, $630 \mathrm{~nm}$ filter also measured $\mathrm{O}\left({ }^{1} \mathrm{D}\right)$ at $200 \mathrm{~km}$, and there are interferences between $\mathrm{O}\left({ }^{1} \mathrm{D}\right)$ and $\mathrm{OH}$ airglows as as observed from a distance in space. We have studied the overlap of two airglows by simulations, and our final analyses show that $\mathrm{OH}$ airglow can be correctly derived with its average peak height of $89 \pm 2.1 \mathrm{~km}$ usually lying within $\pm 10^{\circ}$ latitude about the equator. ISUAL data reveal detailed structures of equatorial $\mathrm{OH}$ airglow such as the existences of a few secondary maxima within the equatorial regions, and the oscillations of the peak latitudes. These results are discussed and compared with previous reports.
\end{abstract}

Key words: $\mathrm{OH}$ airglow, $\mathrm{O}\left({ }^{1} \mathrm{D}\right), 630 \mathrm{~nm}$, ISUAL, FORMOSAT 2, Mesosphere, Tides, Gravity waves

Citation: Nee, J. B., S. D. Tsai, T. H. Peng, R. R. Hsu, A. B. C. Chen, H. T. Su, S. Zhang, T. Y. Huang, P. K. Rajesh, J. Y. Liu, H. U. Frey, S. B. Mende, 2010: OH airglow and equatorial variations observed by ISUAL instrument on board the FORMOSAT 2 satellite. Terr. Atmos. Ocean. Sci., 21, 985-995, doi: 10.3319/TAO.2010.03.12.01(AA)

\section{INTRODUCTION}

In the upper atmosphere above $80 \mathrm{~km}$, some layers of bright emissions are observable in the night. The phenomenon is known as airglow which has attracted great scientific quest since its discovery almost a century ago (Chamberlain 1955). Airglow can be generally found in two height regions. In the mesospheric region at about $90 \mathrm{~km}$, emissions of $\mathrm{Na}, \mathrm{O}, \mathrm{OH}$, and $\mathrm{O}_{2}$ can be observed which are produced mainly by neutral chemistry. A second airglow layer is lying in the ionosphere at about $200-300 \mathrm{~km}$ where emis-

\footnotetext{
* Corresponding author

E-mail:jbnee@phy.ncu.edu.tw
}

sions from $\mathrm{O}, \mathrm{O}^{+}$and other species are produced mainly by excitation due to electron and ionic collisional processes. The mesospheric $\mathrm{OH}$ airglow was first observed by Meinel (1950) and is known as the Meinel bands. The $\mathrm{OH}$ airglow is mainly generated by the exothermic chemical reaction

$\mathrm{H}+\mathrm{O}_{3} \rightarrow \mathrm{OH} *\left(\mathrm{v}^{\prime} \leq 9\right)+\mathrm{O}_{2}$

The $\mathrm{OH}$ molecule can be excited to various vibrational levels up to 9 from which transitions to lower levels are responsible for the emissions in the visible and infrared wavelengths. The chemical reaction depends on the temperature 
as well as on ozone density; both are important parameters for the upper mesosphere. Therefore, the $\mathrm{OH}$ airglow has been extensively studied to investigate the dynamics and chemistry of the upper mesosphere (Takahashi et al. 1989, 1992, 2002; Clemesha et al. 1991; Swenson et al. 1994; Hecht et al. 1995; Mendillo et al. 1997; Taylor et al. 1997; Melo et al. 1999). In the past, $\mathrm{OH}$ airglow has been studied in space by rockets (McDade et al. 1987; Clemesha and Takahashi 1996; Baker and Stair 1988) and several satellite instruments including AE (Atmosphere Explorer E) as reported by Abreu and Yee (1989), WINDII (Wind Imaging Interferometer) and HRDI (High Resolution Doppler Interferometer) both on board the UARS (Upper Atmospheric Research Satellite) reported by Yee et al. (1997) and Zhang and Shepherd (1999). More recently, SABER (Sounding of the Atmosphere using Broadband Emission Radiometry) on board TIMED (Thermosphere Ionosphere Mesosphere Energetics and Dynamics) satellite has been reported by Marsh et al. (2006) and Baker et al. (2007). Compared with ground based measurements, space measurements can provide data about the height and global distributions. For example, both HRDI and WINDII instruments have observed the equatorial enhancement resulting from tidal effects in the upper atmosphere (Yee et al. 1997; Zhang et al. 2001). Similarly, SABER instrument has shown the equatorial enhancement of $\mathrm{OH}$ airglow and the effects of diurnal tides in the low latitudes (Marsh et al. 2006).

The FORMOSAT 2 satellite which was launched on 20 May 2004 has an optical instrument named ISUAL (Imager of Sprites and Upper Atmospheric Lightning (ISUAL) and is used for studying various transient optical emissions produced in the upper atmosphere. By using six filters centered at airglow wavelengths, a CCD camera can observe several types of airglow layers including the red line $\mathrm{O}\left({ }^{1} \mathrm{D}\right)$ $(630 \mathrm{~nm})$, green line $\mathrm{O}\left({ }^{1} \mathrm{~S}\right)(557.7 \mathrm{~nm}), \mathrm{OH}(630 \mathrm{~nm})$, and $\mathrm{O} 2$ A-band $(762 \mathrm{~nm})$. The $\mathrm{OH}$ airglow in the $(9,3)$ band of the Meinel band system has a few lines included in the band pass of the $630 \mathrm{~nm}$ filter. The characteristics of all filters are shown in Table 1.

FORMOSAT 2 satellite has a sun synchronous orbit with an inclination angle $98.9^{\circ}$, so that it returns to the same orbit twice daily at the same local time. Thus, ISUAL is able to study the airglow in the upper atmosphere continuously and repeatedly everyday, which is quite unique compared with many other non sun-synchronous satellites that require many months to return to the same local time. With this continuous daily observation, ISUAL can measure the atmosphere in detail for small variations with scales of a few hundreds kilometers. As will be shown, ISUAL is able to measure airglow intensity over extended regions in scrutiny and to reveal fine latitudinal dependence. Additional advantage of ISUAL is the limb view observation such that integrations of signals along the line of sight can produce enhanced effect for weak emissions. Similar limb view ob- servations have been reported by Mende et al. (1993) made by using an instrument from the Space Shuttle. Mende et al. (1993) reported OH emission had an intensity of over 1300 Rayleigh at a single wavelength $625.6 \mathrm{~nm}$ by using a spectrometer. Although the Meinel band intensity depends on the band wavelength and instrumental characteristics; however, it is easy to see that signals integrated from the limb view path length over $500 \mathrm{~km}$ is much larger than that from the vertical column of about $20 \mathrm{~km}$ if observed from the ground.

The primary purpose of the present research is to develop the methodology for analyzing the $630 \mathrm{~nm}$ airglow observed by ISUAL. The ISUAL instrument with its fine spatial resolution for airglow study has been mentioned. The higher performance also means more challenge in terms of analysis of images. Regarding the $630 \mathrm{~nm}$ airglow, it includes two emissions at different heights Simultaneous measurements of two level airglow has not been made from space before. As will be shown here, ISUAL can indeed observe interesting physics related to the upper atmospheric dynamics. More studies will be made in the future following this one.

This paper is organized as follows. The next section describes about the satellite and instrument information, including the CCD instrument and its characteristics. In section 3, the data processing of two-layer airglow will be described. We will show how to process the ISUAL images to derive information about airglow height and intensity. In section 4 , we describe a simulation study for understanding various interfering phenomena caused observations of double layer airglow of $\mathrm{O}\left({ }^{1} \mathrm{D}\right)$ and $\mathrm{OH}$. In section 5 , we discuss three separate results: latitude and height distribution, equatorial enhancement, and peak latitude oscillations observed during several periods in 2004 and 2007.

Table 1. Filters used for ISUALL CCD Camera.

\begin{tabular}{cccl}
\hline No. & $\begin{array}{c}\text { Wavelength } \\
(\mathbf{n m})\end{array}$ & $\begin{array}{c}\text { FWHM } \\
(\mathbf{n m})\end{array}$ & Airglow and height $(\mathbf{k m})$ \\
\hline 1 & $633-750$ & 120 & $\mathrm{OH}$ \\
2 & 760 & 7 & $\mathrm{O}_{2}$ Atmospheric band \\
3 & 630 & 7 & $\mathrm{OH}$ and $\mathrm{O}\left({ }^{1} \mathrm{D}\right)$ \\
4 & 557.7 & 6 & $\left.\mathrm{O}^{1}{ }^{1} \mathrm{~S}\right)$ \\
5 & 427.8 & 6 & $\mathrm{~N}_{2}{ }^{+}\left(\mathrm{B}^{2} \Sigma_{\mathrm{g}}{ }^{+}\right) 1^{\text {st }}$ negative band \\
& & & \\
\hline
\end{tabular}




\section{SATELLITE AND ISUAL INSTRUMENT}

FORMOSAT 2 was launched on 21 May 2004 to a height of $890 \mathrm{~km}$ with 14 orbits around the earth everyday as shown in Fig. 1. The $\mathrm{OH}$ airglow was usually measured from orbits 10 and 11 at approximately midnight local time by looking at a direction perpendicular to the satellite's path (to the north) over a distance about $3000 \mathrm{~km}$ eastward from the satellite orbit. Therefore, airglow lying above the orbit 8 or 9 is observed while the satellite was moving along orbits 10 and 11 from south to north in the night side of the earth. The highest latitude observed is determined by the darkness of sky background. For summer time in the northern hemisphere, the observed latitudes are usually low (about $30^{\circ}$ ) because of solar scattering from the dayside atmosphere that will enhance the background signals such that the instrument will be turned off.

ISUAL has a CCD camera along with several photometers to observe the atmospheric emissions. The CCD camera has a micro-channel plate to enhance the signal condition. The instrument nominally points approximately $26^{\circ}$ down from the local horizontal with a field of view of $20^{\circ}$ horizontal and $5^{\circ}$ vertical. Each CCD picture has 524 (horizontal) $\times 128$ (vertical) pixels corresponding to a window of $1200 \mathrm{~km} \times 270 \mathrm{~km}$ of the upper atmosphere as shown in Fig. 2. A spatial resolution of about $2.14 \mathrm{~km}$ per pixel has been determined from the calibration. The whole picture covers about 10 degrees of latitudes and heights up to ionosphere depending on the satellite attitude. More information of the scientific objectives, the payload instrument, and operation modes of the ISUAL project are given by Chern et al. (2003). Descriptions about the observations of airglow at $630 \mathrm{~nm}$ by ISUAL have been described in separate papers (Nee and Peng 2008; Rajesh et al. 2009).

The observation can be made by any one of six different filters to spectrally select the observational wavelength. The \#3 filter centered at $630 \mathrm{~nm}$ with a FWHM of $7 \mathrm{~nm}$ was designed to observe $\mathrm{O}\left({ }^{1} \mathrm{D}\right)$ airglow; however, it also sees the $(9,3)$ band of the Meinel bands of the $\mathrm{OH}$ airglow. Although the $(9,3)$ band is relatively weak, it is enhanced by the limb view observation because of integration of the emissions over a long path along the line of sight. Depending on the pitch angle of the satellite, ISUAL can measure $\mathrm{OH}$ airglow only (including some earth surfaces), or measure higher heights up to ionosphere to include both $\mathrm{OH}$ and $\mathrm{O}\left({ }^{1} \mathrm{D}\right)$ airglows. Figure 2a shows an image of a single layer of $\mathrm{OH}$ airglow and Fig. $2 b$ shows two layers of airglow of $\mathrm{O}\left({ }^{1} \mathrm{D}\right)$ and $\mathrm{OH}$. In Fig. 2a or b, the images appear to be brighter in the left hand side than the right hand side because there are two CCD chips joined together in the camera.

In 2004 when the satellite was just launched, ISUAL underwent several test periods, one of these was the observa-

ROCSAT-2/ISUAL ORBITS

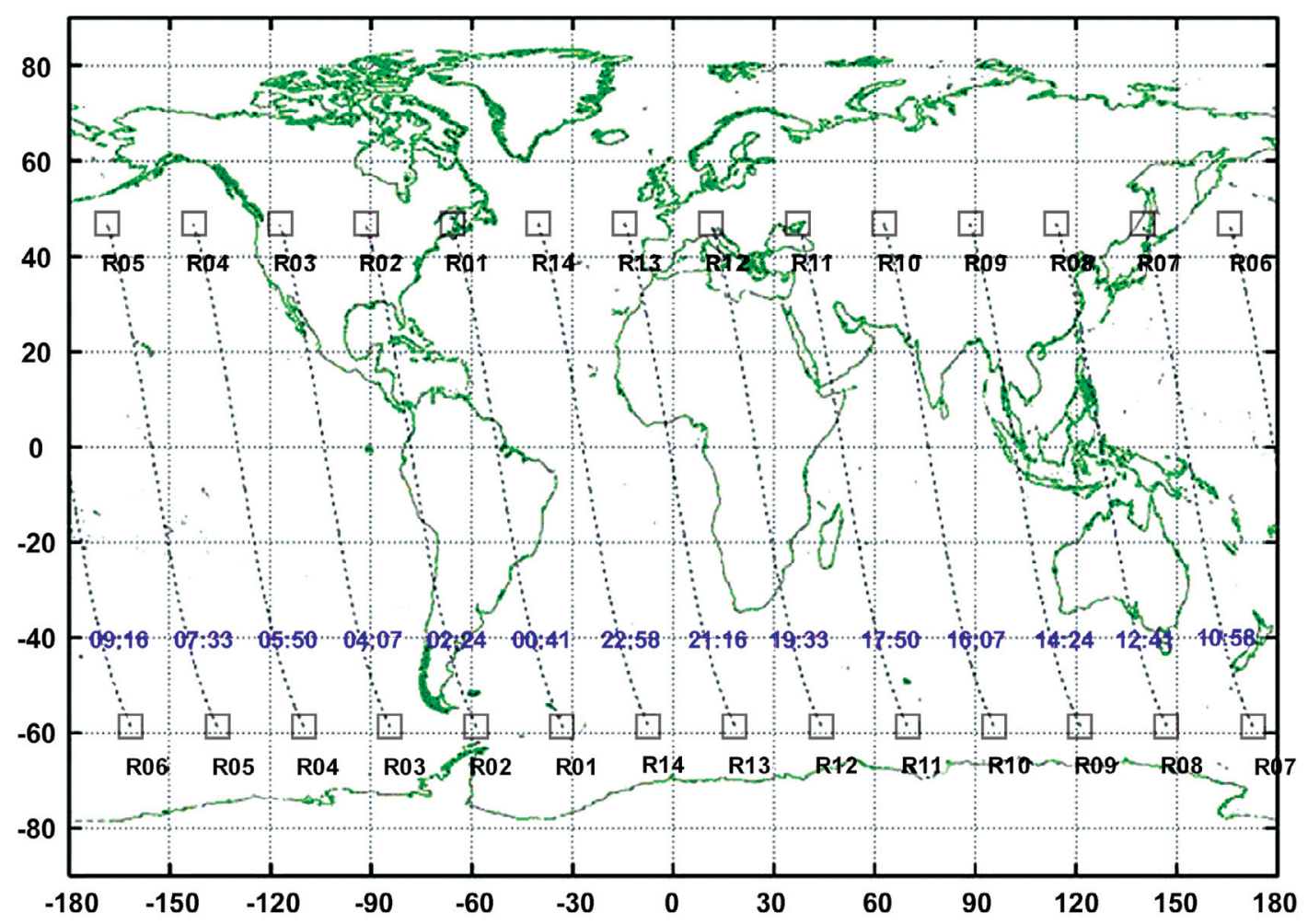

Fig. 1. ISUAL orbits (R01 - R14) and times of visit everyday. 


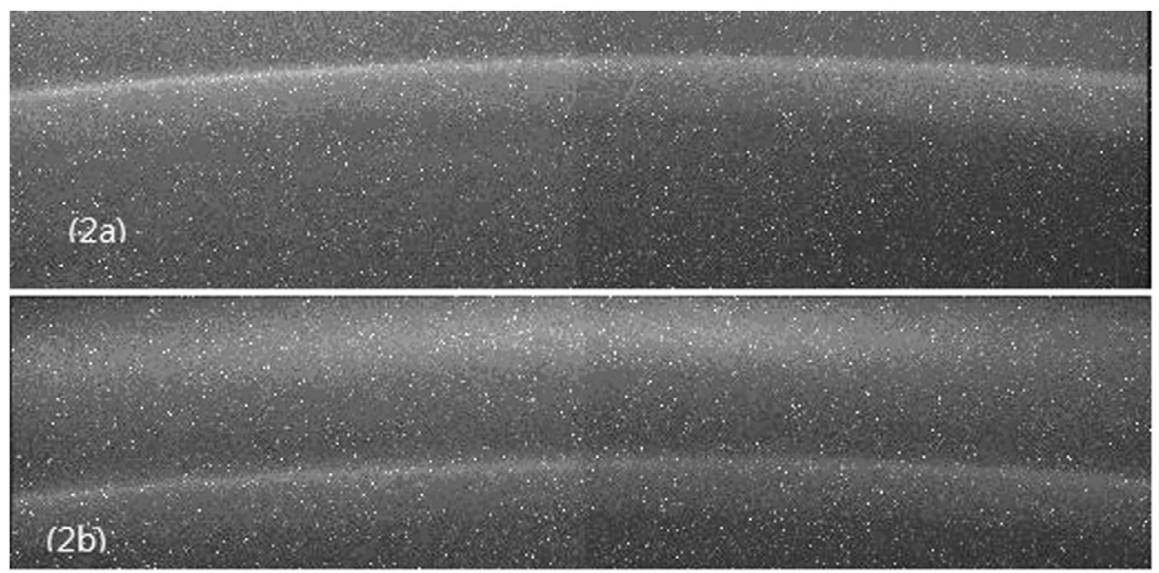

Fig. 2. (a) A limb view image of $\mathrm{OH}$ airglow measured on 7 October 2004. This is the first image out of 129 total images measured this day. There are 128 vertical and 524 horizontal pixels in this image with the $\mathrm{OH}$ airglow layer located at vertical pixel positions about 90 - 100 of the image. The Earth's surface which is not clearly shown here lies at the vertical pixels below \#70. (b) Two layers of airglow measured on 15 October 2004. The upper layer is the red line of $\mathrm{O}\left({ }^{1} \mathrm{D}\right)$ and the lower layer is $\mathrm{OH}(9,3)$ band. The intensity is brighter in the left hand side than the right hand side because there are two CCD chips joined together in the camera.

tion of the $630 \mathrm{~nm}$ airglow from 7 to 13 October 2004 (Nee and Peng 2008). The continuous measurements were carried out each day (except 12 October) to produce 129 records of airglow images each consisting of $120 \times 524$ pixels covering a range of $250 \mathrm{~km}$ (in height) $\times 1200 \mathrm{~km}$ (horizontal, or about 10 degree latitudes) as shown in Fig. 2. There are large overlaps of latitudes between neighboring records which consume a lot of computer memory. This practice was changed in 2007 so that only 40 records were taken later, although 40 records still produce large overlaps. But averaging of these images will give a good signal to noise ratio.

\section{DATA PROCESSING}

The daily 40/129 records carry useful information about the latitudinal coverage of the $\mathrm{OH}$ airglow. These pictures are processed to study airglow variations over height and latitude by the following method. First, each image is treated by binning the central 10 columns to derive a horizontally averaged profile. Then all 40/129 records measured for the day are combined to produce a contour diagram as shown in Fig. 3. Selection of central pixels can avoid the edge effect in imaging processing since the side pixels are less accurate in the radiometry calibration. Also, the longitude and latitude of the pixels are determined by a projection based on the satellite position and orientation. We found the side pixels are less accurate in determining the longitude and latitude compared with the central ones. By binning more pixels (such as 70 or 100 central pixels), we found similar results but with reduced detailed structure in airglow images produced.

Airglow vertical profiles are derived by an onion-peel retrieval process employed in the WINDII data processing with the procedures explained in Fig. 4 for the $30^{\text {th }}$ record of the day (7 October 2004). As shown in Fig. 4a, the $250^{\text {th }}$ column in the image is fitted linearly to find the background signals, which are mainly contributed by various atmospheric emissions and instrument noises. The background level is determined by a line fitting of the upper and lower regions. Figure $4 \mathrm{~b}$ shows the height distribution of signals after removing the background. The resulting signals show fluctuation and spikes due to irregular pixels or electronic noises. The smoothed airglow signals are then carried out to derive the vertical distribution of integrated emissions in Rayleigh unit as shown in Fig. 4c. Finally $\mathrm{OH}$ profile in terms of volume emission rate (photons $\mathrm{cm}^{-3}$-s) is derived as shown in Fig. 4d. A total of 40 or 129 profiles are combined to derive the peak emission and height of the day as shown in Table 2.

\section{SIMULATION}

ISUAL observes $\mathrm{O}\left({ }^{1} \mathrm{D}\right)$ and $\mathrm{OH}$ airglow simultaneously with images sometimes showing extended signals lying between $\mathrm{O}\left({ }^{1} \mathrm{D}\right)$ and $\mathrm{OH}$ layers. In Fig. 3, we have already seen both layers are connected with weak emissions. Figure 5 shows results of a global measurement carried out in 2009 for double-layer airglow as the satellite traveled through all 14 orbits for two days. The results are not analyzed in this paper but used for explaining the overlap of signals. Figure 5a shows an example of serious interferences where enhanced signals lying not only between the two airglow layers but also below the $\mathrm{OH}$ airglow extending down to about $50 \mathrm{~km}$. The enhanced layers can be real due to strong activities in the upper atmosphere, but more likely caused by interferences from the upper layer $\mathrm{O}\left({ }^{1} \mathrm{D}\right)$ as shown in Fig. 5c (Figure $5 b$ is the inverted result to be 

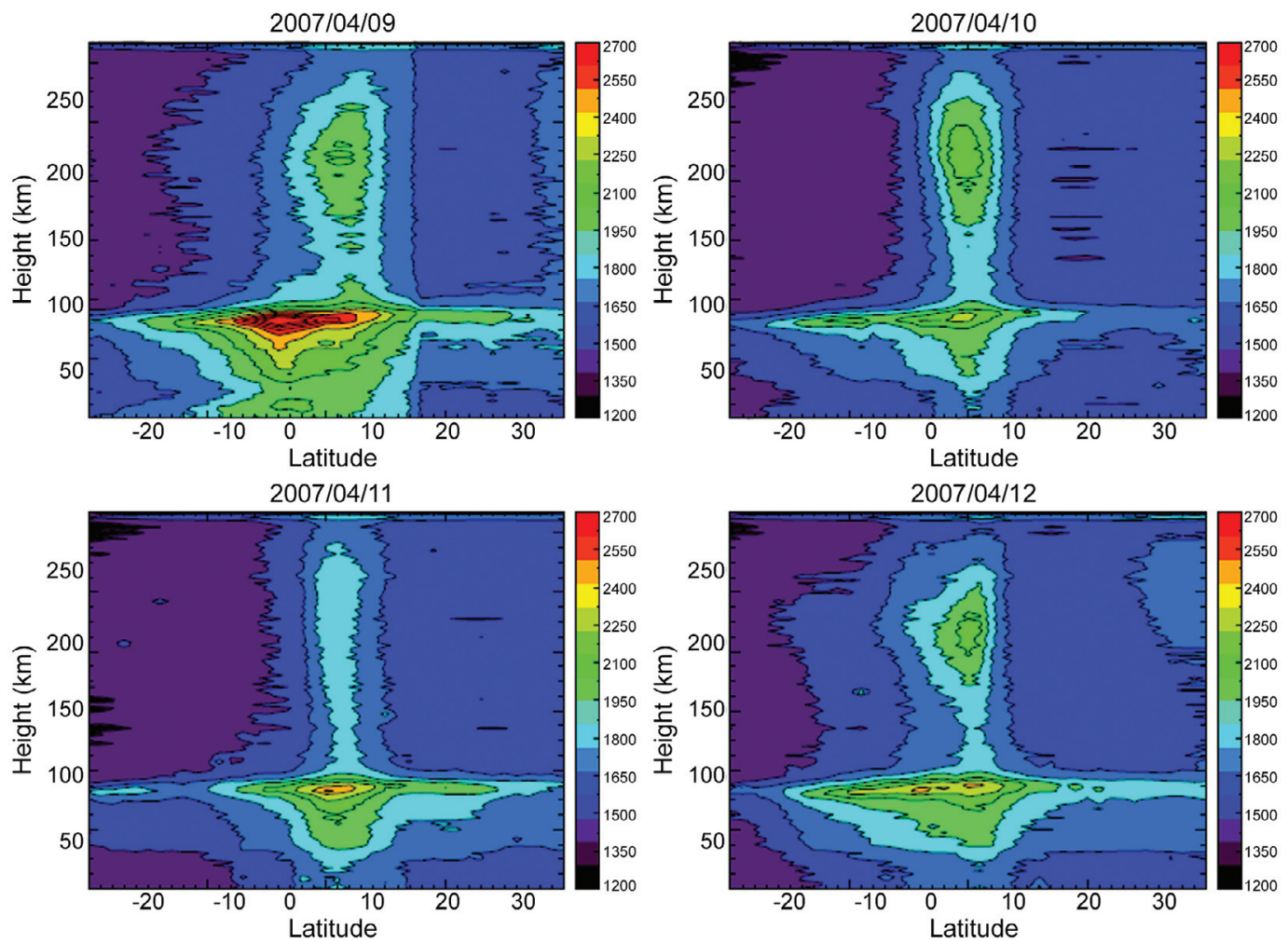

Fig. 3. Contour diagram of airglow layers in height $(\mathrm{km})$ versus latitude (degree) measured on 9 - 12 April 2007 . The height range is 50 - $250 \mathrm{~km}$ and latitudes are $-20^{\circ} \sim 30^{\circ}$. The upper $\mathrm{O}\left({ }^{1} \mathrm{D}\right)$ at about $200-250 \mathrm{~km}$ is connected with the lower $\mathrm{OH}$ layer caused by observations from an upper layer satellite as explained in the text. The signals of $\mathrm{OH}$ airglow may include some signals of $\mathrm{O}\left({ }^{1} \mathrm{D}\right)$ layer such that overlapped signals appear in between both layers and below $\mathrm{OH}$ layer.
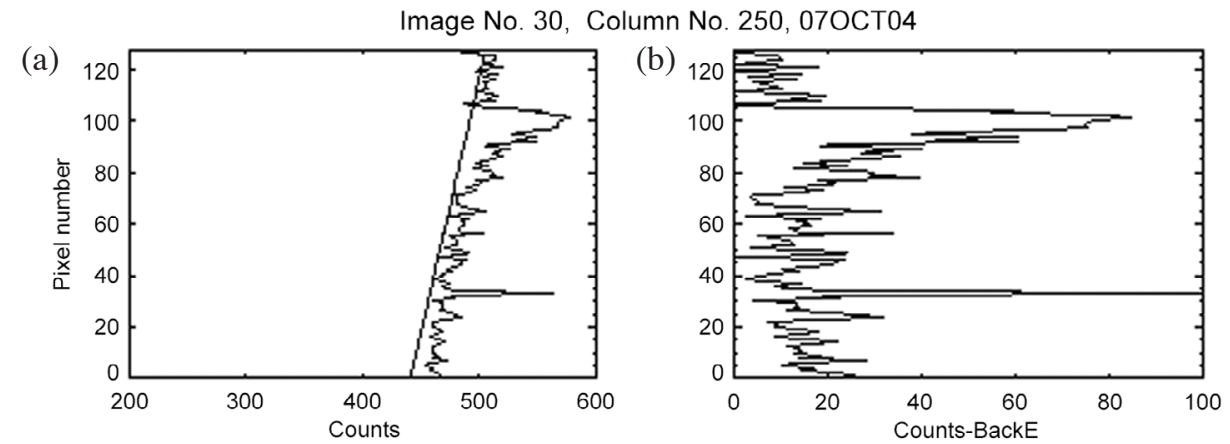

$\mathrm{OH}(9,3)$ VER Profile
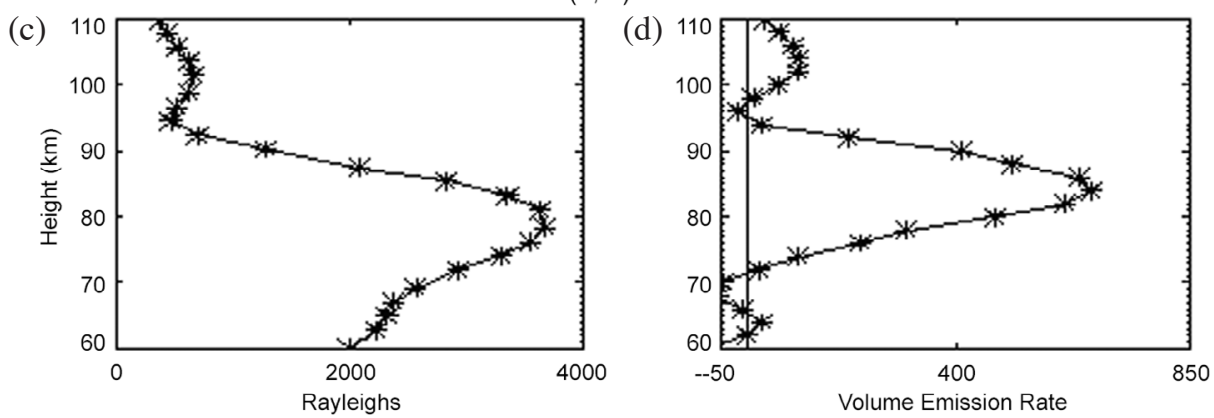

Fig. 4. An example of processing of $\mathrm{OH}$ image based on record 30 (out of 129 total records) for 7 October 2004. The central pixel along column \#250 is treated by the following steps: (a) Background signals are determined by a line fitting of upper and lower rows as shown in the figure. (b) A height distribution of the signals after removal of background emission (BackE). The vertical coordinate is pixel number. (c) Averaged signals from 10 columns are derived in terms of Rayleigh as a function of height $(\mathrm{km})$ which is converted from pixel number. (d) Retrieved profile of OH airglow emission rate. 
Table 2. A summary of $\mathrm{OH}$ measurements in 2004 and 2007.

\begin{tabular}{|c|c|c|c|c|c|}
\hline Observation period & $\begin{array}{c}\text { Average peak } \\
\text { height and error }(\mathbf{k m})\end{array}$ & $\begin{array}{c}\text { Average emission rate } \\
\left.\text { and error (photon } \mathrm{cm}^{-3}-\mathrm{s}\right)\end{array}$ & $\begin{array}{l}\text { Intensity } \\
\text { variation }\end{array}$ & Orbit & $\begin{array}{l}\text { Latitudes: range } \\
\text { covered (degree) }\end{array}$ \\
\hline $07-17$ October $2004 *$ & $86.0 \pm 2.2$ & $682 \pm 141$ & $20.7 \%$ & 10 & $-2.52 \sim 5.94$ \\
\hline 09 - 22 April 2007 & $89.4 \pm 1.2$ & $679 \pm 47$ & $7.0 \%$ & 10 & $-10.82 \sim 9.16$ \\
\hline 07 - 16 August 2007 & $90.7 \pm 1.5$ & $495 \pm 122$ & $24.7 \%$ & 11 & $-10.15 \sim 15.7$ \\
\hline 06 - 14 October 2007 & $90.4 \pm 1.7$ & $568 \pm 82$ & $14.6 \%$ & 11 & $11.13 \sim 14.29$ \\
\hline 10 - 17 November 2007 & $90.8 \pm 2.5$ & $556 \pm 109$ & $19.7 \%$ & 4 & $-5.26 \sim 14.04$ \\
\hline Average & 89.4 & 604 & & & \\
\hline
\end{tabular}

* There is no data on 12 October 2004.

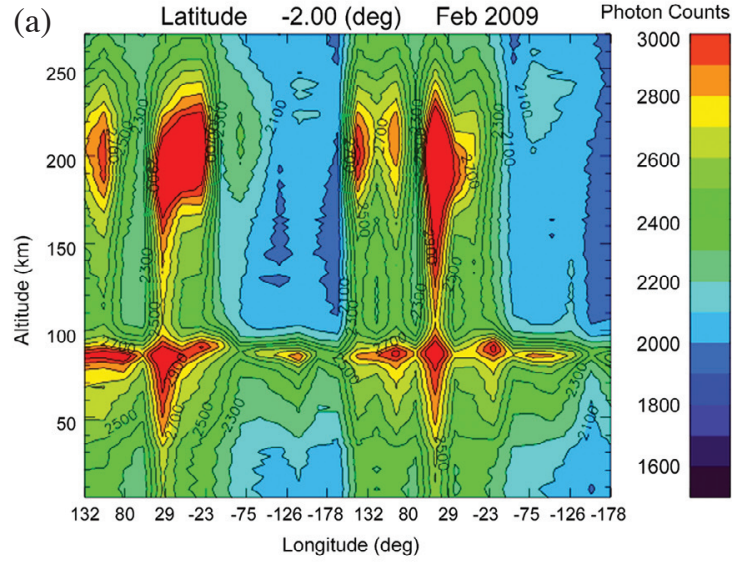

(c)

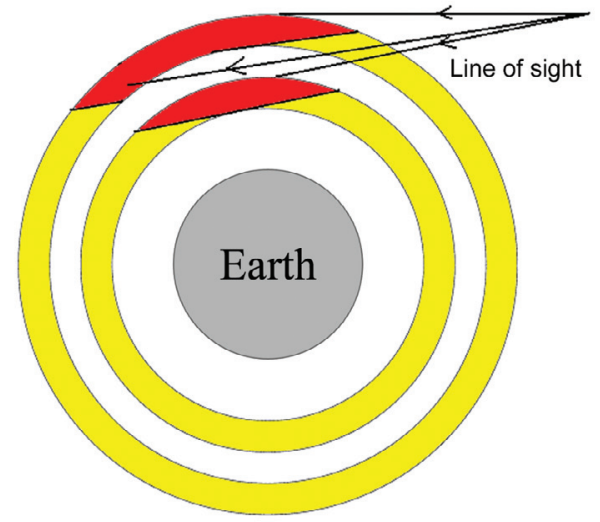

explained later). As the space craft at $890 \mathrm{~km}$ sees the $\mathrm{OH}$ airglow below it has to look through an outer layer of $\mathrm{O}\left({ }^{1} \mathrm{D}\right)$. If the $\mathrm{O}\left({ }^{1} \mathrm{D}\right)$ is spread out in space, the signals of the upper layer can superimpose on the lower $\mathrm{OH}$ layer as shown in Fig. 5c. Rajesh et al. (2009) studied several cases of $630 \mathrm{~nm}$ data and concluded the interferences of $\mathrm{O}\left({ }^{1} \mathrm{D}\right)$ is severe. We carried out a simulation to understand the influences of the upper layer $\mathrm{O}\left({ }^{1} \mathrm{D}\right)$ on the signals of $\mathrm{OH}$. This is done by assuming two airglow layers with Gaussian intensity distributions at 90 and $200 \mathrm{~km}$ with different widths. A case of thick

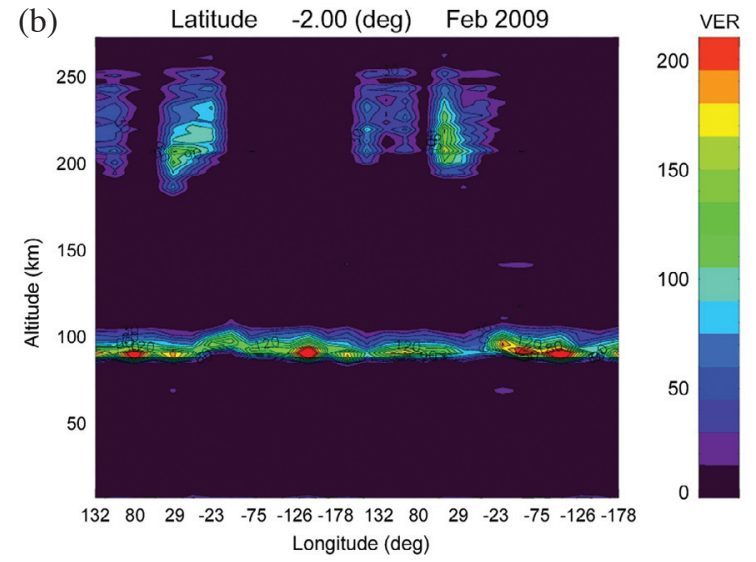

Fig. 5. (a) $630 \mathrm{~nm}$ airglow observed on 25 February 2009 showing spread of intensity at heights between layers of $\mathrm{O}\left({ }^{1} \mathrm{D}\right)$ and $\mathrm{OH}$ was observed. (b) The inverted airglow volume emission rate profile shows free interference between two airglow layers. (c) The spread signals are produced when $\mathrm{O}\left({ }^{1} \mathrm{D}\right)$ layer is extended over the $\mathrm{OH}$ layer, so that the line of sight intensity of observed from satellite shows overlapped signals between two layers as shown in the figure.

layer with widths of about $100 \mathrm{~km}$ is shown in Fig. 6a. By integration of signals along the line of sight, a synthetic image can be produced as shown in Figs. $6 \mathrm{~b}-\mathrm{c}$. These synthetic images are then retrieved with the inversion processes to re-derive the original airglow distribution as shown in Fig. $6 \mathrm{c}$. We found for cases of overlapped emission layers with thick widths of over $100 \mathrm{~km}$ as shown in Fig. 6a, the original peak heights of both airglow layer can still be derived by the retrieval processes, although there is a undercut at the shoulder or bottom part of the airglow layer. However, 
the peak latitudes for both $\mathrm{O}\left({ }^{1} \mathrm{D}\right)$ and $\mathrm{OH}$ are retrieved. We are therefore confident that the retrieval software can produce realistic height and profiles of airglow. Figure $5 \mathrm{~b}$ in the previous graph shows results of inverted process, where
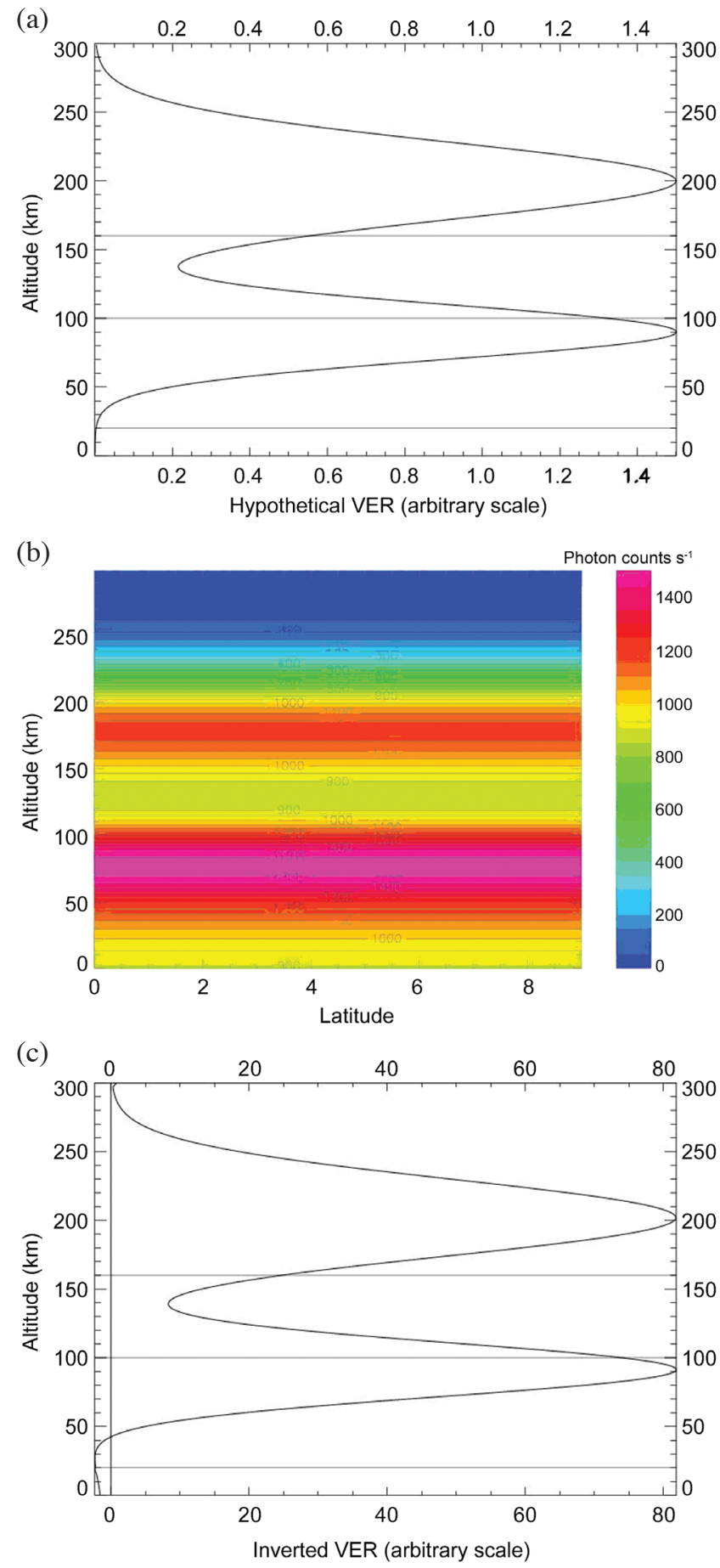

Fig. 6. Simulation of interferences of double layer airglow $\mathrm{O}\left({ }^{1} \mathrm{D}\right)$ and $\mathrm{OH}$. (a) First, two Gaussian profiles are generated with central height at 90 and $205 \mathrm{~km}$ and each with thickness: $160 \mathrm{~km}$ for the upper layer and $60 \mathrm{~km}$ for the lower layer. (b) A synthetic contour diagram is generated by integration of layers along the line of sight. (c) Retrieved airglow profiles showing same height distribution. overlapping layers below $\mathrm{O}\left({ }^{1} \mathrm{D}\right)$ and $\mathrm{OH}$ are removed and original height distributions are derived.

\section{RESULTS AND DISCUSSION}

\subsection{Latitude and Height Distribution}

Results of $\mathrm{OH}$ airglow measurements carried out in October 2004 and 2007 (for weeks in April, October, and November) are summarized in Table 2. Based on processes described above, the average peak heights of $\mathrm{OH}$ airglow are determined for each period. Results of Table 2 may present seasonal dependence and long term variation (and could be related with solar effect after the 2005 - 06 solar minimum); however, more future data are needed to confirm this point. The average of all data gives the $(9,3)$ band a peak height of $88.9 \pm 1.9 \mathrm{~km}$ and volume emission rate $574 \pm 97$ (photon $\mathrm{cm}^{-3}-\mathrm{s}$ ). The peak latitudes lie within equatorial latitudes of about $\pm 10^{\circ}$, consistent with equatorial enhancement.

The average peak height reported here may be compared with previous studies. HRDI data showed $\mathrm{OH}$ airglow with an average peak height of $88 \mathrm{~km}$ (Yee et al. 1997), and WINDII data show a peak height of $87 \mathrm{~km}$ (Zhang and Shepherd 1999). Liu and Shepherd (2006) reported a Gaussian fitting with peak height about $86 \mathrm{~km}$ for equatorial latitudes from -20 to 20 degree (A typical integrated emission rate from their Fig. 2 is 60 Rayleigh. By using their Table 1 for a1 $=-0.0673$, we get the typical altitude $89.6+(-0673 *$ $60)=85.5 \mathrm{~km}$, neglecting the seasonal terms.). Mende et al. (1993) reported the limb view $\mathrm{OH}$ airglow with a height of $88 \mathrm{~km}$. Baker and Stair (1988) by various rocket flights found the peak height of $\mathrm{OH}$ airglow might vary between 82 and $99 \mathrm{~km}$, depending on location (latitude and longitude), observation strategy, and $\mathrm{OH}$ vibrational state. The mean rocket height for $\mathrm{OH}$ airglow was $86.8 \pm 2.6 \mathrm{~km}$ with a layer thickness of $8.6 \pm 3.1 \mathrm{~km}$. The difference in peak heights of ISUAL and WINDII is within one pixel resolution (2.14 $\mathrm{km})$. Actually, all satellites observed $\mathrm{OH}$ by different strategies. WINDII observed a single rotational line: the $\mathrm{P}(3)$ line of $(8,3)$ band, HRDI for $(9,4)$ band, and SABER for several bands with upper level $\mathrm{v}^{\prime}=4,5,8$, and 9 and emissions in the infrared wavelengths. Therefore, we expect some differences in $\mathrm{OH}$ airglow peak heights from these measurements.

There is a concern about the dependence of the peak height on the internal state of $\mathrm{OH}$ molecule which is related with the production mechanism. The $(9,3)$ band is the highest level produced by reaction $\mathrm{H}+\mathrm{O}_{3} \cdot \mathrm{OH}\left(\mathrm{v}^{\prime}=9\right)$ can only decay to lower vibrational level $\mathrm{v}^{\prime}$, but lower levels may be produced from chemical reactions, radiating or relaxation from upper level. In addition to $\mathrm{H}+\mathrm{O}_{3}$, excited states of $\mathrm{OH}$ may be produced by $\mathrm{O}+\mathrm{HO}_{2}$ or $\mathrm{H}+\mathrm{HO}_{2}$ for $\mathrm{OH}\left(\mathrm{v}^{\prime} \leq 6\right)$. The relaxation depends on collisions with ambient atmosphere. Therefore, vibrational levels of $\mathrm{OH}$ may 
be height dependent. Simulation studies have been made to understand the height distributions for $v^{\prime}=6-9$ (Le Texier et al. 1987; McDade et al. 1991). By using SABER infrared data, which measured $\mathrm{v}^{\prime}=4,5,8$, and 9 of $\mathrm{OH}$, Baker et al. (2007) show the height difference of a few kilometers between the higher and lower vibrational levels. Future studies of the height dependence will be useful for understanding the chemistry of $\mathrm{OH}$ airglow as well as the dynamics and photochemistry of the mesopause region.

\subsection{Equatorial Enhancement}

Since ISUAL is able to continuously scan the upper air as the satellite travels around the earth, structures of airglow layers can be carefully scrutinized. As shown in Fig. 7a, the contour diagram of $\mathrm{OH}$ airglow for 14 April 2007 shows several maxima in equatorial region varying from the Southern Hemisphere to Northern Hemisphere. On 7 August 2007, as shown in Fig. 7b, we found these maxima in the equatorial regions are lying at latitudes $-6.7^{\circ}$, $4.1^{\circ}, 8.7^{\circ}$, and $11.8^{\circ}$, with northern peaks stronger than the southern ones. Secondary maxima lying near mid-latitude at about $\pm 20^{\circ}$ also exist, but they seem to have less intensity than those of the equatorial maxima. Figure 8 shows the contour diagrams for $\mathrm{OH}$ airglow on 9 - 13 August. We can easily observe multiple peaks for most of the day. On 12 August, the equatorial enhancement is particularly strong with intensity enhanced over $15^{\circ}$ of latitudes. We are currently investigating this particular event in terms of the dynamics of the mesosphere.

Diurnal tide propagation is considered to be a major mechanism for equatorial enhancement of airglow intensities. $\mathrm{OH}$ airglow can be enhanced by reaction (1) because of the increment of $\mathrm{O}_{3}$ caused by transport of oxygen atoms from the upper level, or by temperature perturbations in the

(a)

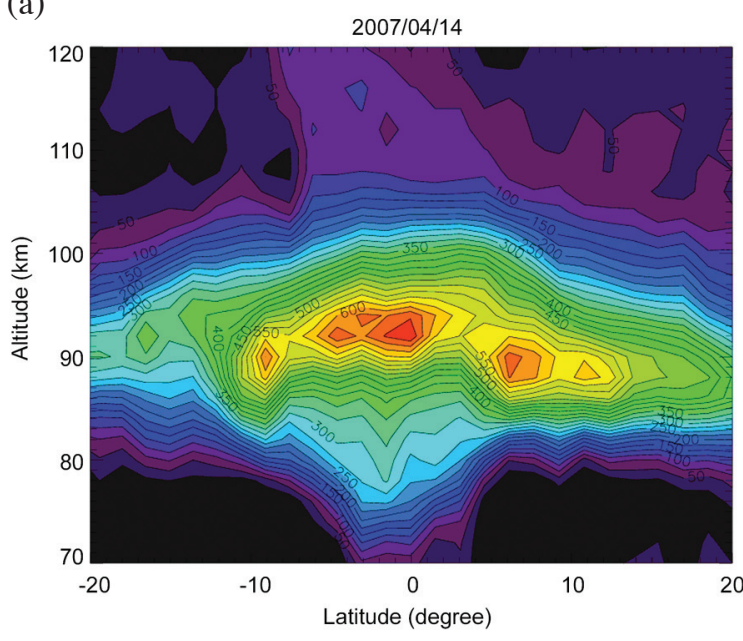

mesosphere (Abreu and Yee 1989; Zhang and Shepherd 1999; Marsh et al. 2006). Variation of airglow intensity can be also caused by the gravity waves as reported by many authors using various ground based imaging instruments (Swenson and Mende 1994; Hecht et al. 1995; Taylor et al. 1997; Fritts and Alexander 2003; Shiokawa et al. 2003). Wave activities in equatorial regions can cause intensity variations of $50 \%$ at a fixed site (Hecht et al. 1995). The small scale variation found by ISUAL seems to be more likely related with the gravity wave activities in the low latitudes, which are abundant due to convectivity in the region (Oberheide et al. 2002). The scale of variation due to tidal effects is expected to be larger.

\subsection{Peak Latitude Oscillations}

Compared with previous studies which all showed equatorial enhancement, ISUAL can locate the position of variations more accurately. Figure 9 shows plots of the variations of the peak latitudes with day number based on the 2007 data. The peak latitudes in August show a smooth variation; however, data of October and November data show oscillations of peak latitudes from south to north. The oscillations are with periods of two to three days. Similar oscillation was observed in October data in 2004 as reported by Nee and Peng (2008).

Previous ground based observations of $\mathrm{O}, \mathrm{Na}, \mathrm{OH}$, and $\mathrm{O}_{2}$ airglow have shown intensity variations of a two day period (Takahashi et al. 2002). Ward et al. (1996) reported a two-day wave for the green line airglow from WINDII observations, with the strongest signals in July and August and a weaker signal in October. Radar wind data have shown two-day wave in the mesospheric regions (Harris and Vincent 1993; Fritts and Isler 1994; Thayaparan et al. 1997). Seen at ground at a fixed point, airglow intensity will show

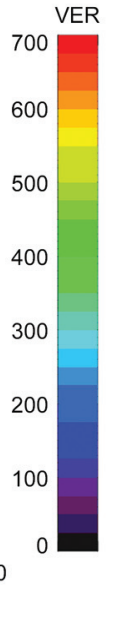

(b)

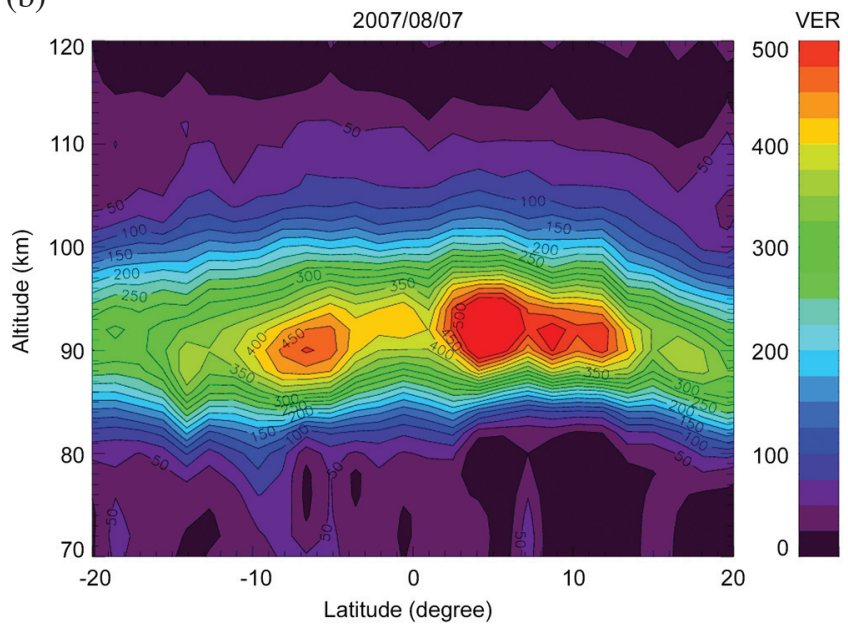

Fig. 7. Daily variation of the peak latitude of OH airglow observed in (a) April 2007 and (b) August 2007. 

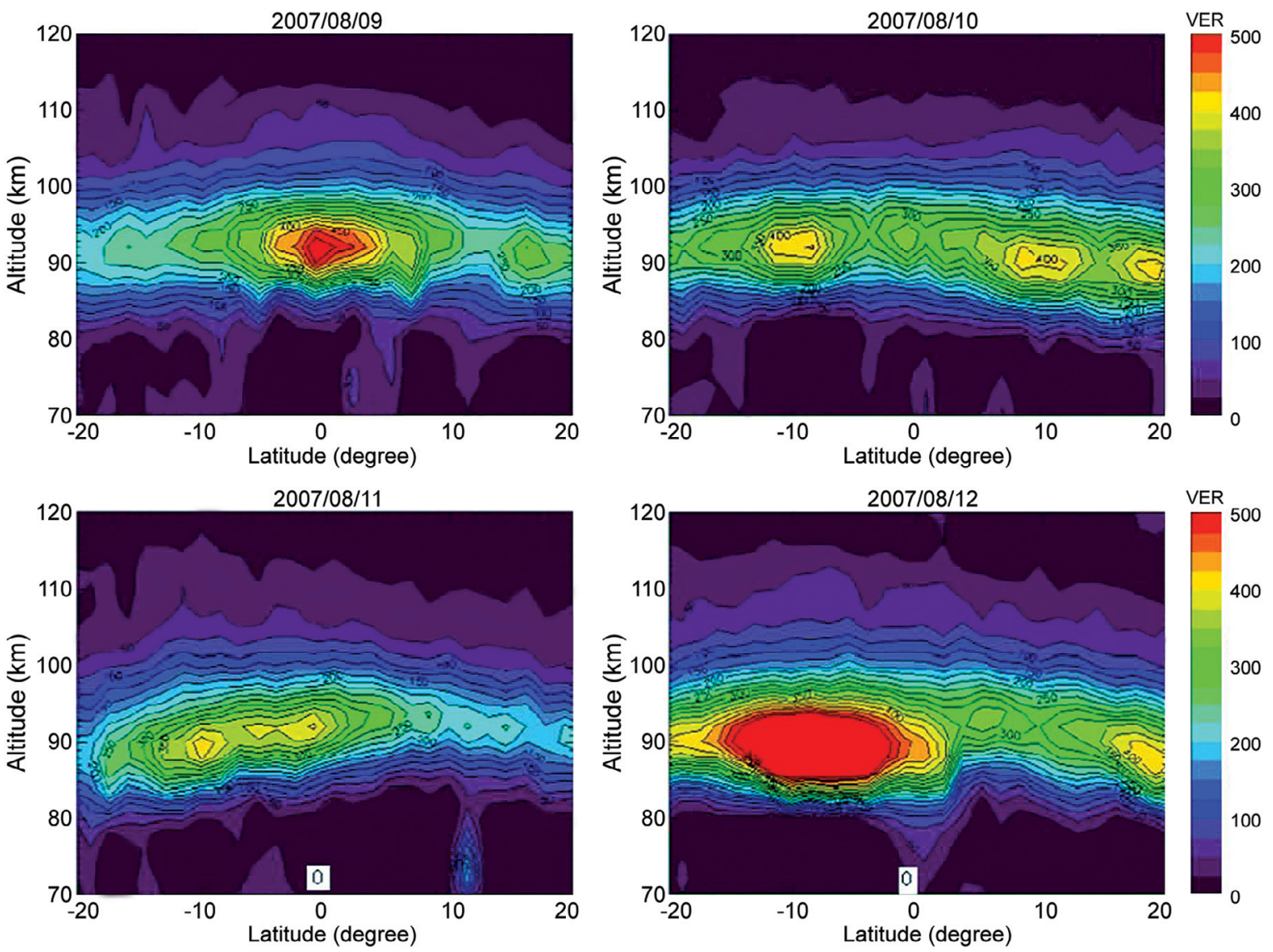

Fig. 8. The OH airglow distribution for 09 - 12 August 2007 (starting upper left in clockwise order). Multiple maxima appeared in the latitudinal region of -20 to +20 degrees in the top two plots and enhanced maximum over large latitudes in the last plot of 12 August 2007.

a two day variational period as showed in these reports. Observed from space, ISUAL will see a different pattern compared with the ground based observations since the satellite travels through a range of latitudes. However, variation of peak emission with a south-north oscillation as observed by ISUAL will also result a two day oscillation if observed from ground. The similarity is not completely established, but more observations will help to understand these activities in the future.

\section{CONCLUSIONS}

OH airglow is observed by FORMOSAT 2 satellite by using a CCD camera at $630 \mathrm{~nm}$. The FORMOSAT 2 satellite with its sun-synchronous orbit and limb view observation has an advantage to measure atmospheric variations in detail. In this paper, we report methodology developed for analyzing ISUAL data. ISUAL observations of $630 \mathrm{~nm}$ double layer airglow provide interesting data for analyzing the phenomena but also present difficulties in analysis. The image processing and data retrieval are discussed and simulations are performed to understand the superposition of upper layer $\mathrm{O}\left({ }^{1} \mathrm{D}\right)$ on $\mathrm{OH}$. Results of measurements during

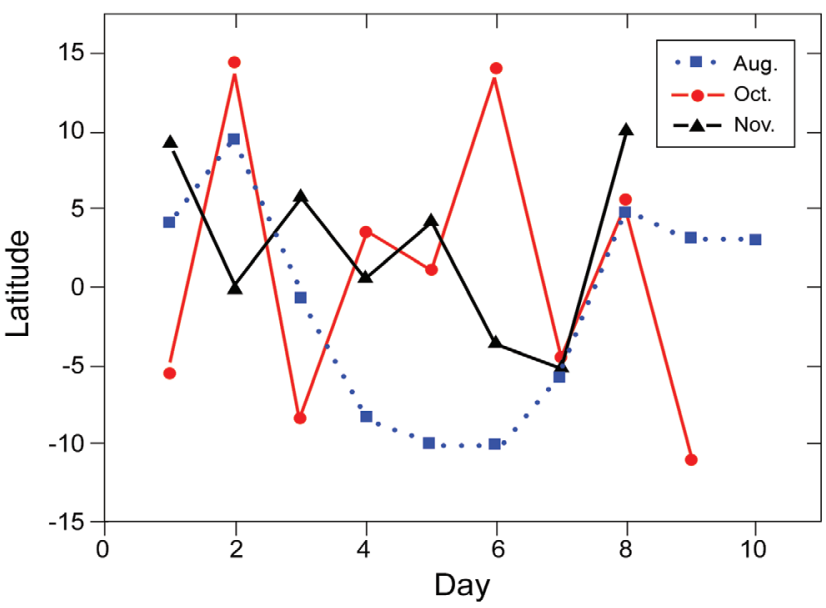

Fig. 9. Daily variation of peak latitudes $\mathrm{OH}$ airglow measured in $\mathrm{Au}-$ gust, October, and November 2007. Both the October and November data show oscillation behavior of peak $\mathrm{OH}$ latitudes. The day number in the abscissa is the relative number started from the first day of the observation.

several periods in 2004 and 2007 are reported here. From the image data, we determined the peak height and emission rate in equatorial regions. They compare closely with 
previous data, but differences can exist due to observational strategy. ISUAL data supports not only the equatorial enhancement, but also fine structure variations of airglow in equatorial regions such as presence of multiple maxima. Furthermore, the peak latitudes show an oscillation period of two to three days.

Acknowledgements We wish to thank NSPO for supporting this research through a grant number: 96-NSPO(B)ISUAL-FA09-01-sub project 3 and NSPO-S-099015. We would like to thank Gordon Shepherd for continuing encouragement and advice provided in the past few years.

\section{REFERENCES}

Abreu, V. J. and J. H. Yee, 1989: Diurnal and seasonal variation of the nighttime $\mathrm{OH}(8-3)$ emission at low latitudes. J. Geophys. Res., 94, 11949-11957, doi: 10. 1029/JA094iA09p11949. [Link]

Baker, D. J. and A. T. Stair Jr., 1988: Rocket measurements of the altitude distributions of the hydroxyl airglow. Phys. Scr., 37, 611-622, doi: 10.1088/0031-894 9/37/4/021. [Link]

Baker, D. J., B. K. Thurgood, W. K. Harrison, M. G. Mlynczak, and J. M. Russell, 2007: Equatorial enhancement of the nighttime $\mathrm{OH}$ mesospheric infrared airglow. Phys. Scr., 75, 615-619, doi: 10.1088/0031-8949/75/5/004. [Link]

Chamberlain, J. W., 1995: Physics of the Aurora and Airglow, American Geophysical Union, Washington, DC.

Chern, J. L., R. R. Hsu, H. T. Su, S. B. Mende, H. Fukunishi, Y. Takahashi, and L. C. Lee, 2003: Global survey of upper atmospheric transient luminous events on the ROCSAT-2 satellite. J. Atmos. Sol.-Terr. Phys., 65, 647-659, doi: 10.1016/S1364-6826(02)00317-6. [Link]

Clemesha, B. R. and H. Takahashi, 1996: Rocket-borne measurements of horizontal structure in the $\mathrm{OH}(8,3)$ and Na D airglow emissions. Adv. Space Res., 17, 8184, doi: 10.1016/0273-1177(95)00733-U. [Link]

Clemesha, B. R., H. Takahashi, P. P. Batista, Y. Sahai, and D. M. Simonich, 1991: The temperature dependence of airglow emissions from the upper mesosphere and lower thermosphere. Planet. Space Sci., 39, 13971404, doi: 10.1016/0032-0633(91)90019-7. [Link]

Fritts, D. C. and J. R. Isler, 1994: Mean motions and tidal and two-day structure and variability in the mesosphere and lower thermosphere over Hawaii. J. Atmos. Sci., 51, 2145-2164, doi: 10.1175/1520-0469(1994)051<21 45:MMATAT>2.0.CO;2. [Link]

Fritts, D. C. and M. J. Alexander, 2003: Gravity wave dynamics and effects in the middle atmosphere. Rev. Geophys., 41, 1003, doi: 10.1029/2001RG000106. [Link]

Harris, T. J. and R. A. Vincent, 1993: The quasi-two-day wave observed in the equatorial middle atmosphere. J. Geophys. Res., 98, 10481-10490, doi: 10.1029/93JD 00380. [Link]

Hecht, J. H., S. K. R. Howat, R. L. Walterscheid, and J. R. Isler, 1995: Observations of variations in airglow emissions during ALOHA-93. Geophys. Res. Lett., 22, 2817-2820, doi: 10.1029/95GL03019. [Link]

Le Texier, H., S. Solomon, and R. R. Garcia, 1987: Seasonal variability of the $\mathrm{OH}$ Meinel bands. Planet. Space Sci., 35, 977-989, doi: 10.1016/0032-0633(87)90002X. [Link]

Liu, G. and G. G. Shepherd, 2006: An empirical model for the altitude of the $\mathrm{OH}$ nightglow emission. Geophys. Res. Lett., 33, L09805, doi: 10.1029/2005GL025297. [Link]

Marsh, D. R., A. K. Smith, M. G. Mlynczak, J. M. Russell III, 2006: SABER observations of the OH Meinel airglow variability near the mesopause. J. Geophys. Res., 111, A10S05, doi: 10.1029/2005JA011451. [Link]

McDade, I. C., 1991: The altitude dependence of the $\mathrm{OH}\left(\mathrm{X}^{2} \Pi\right)$ vibrational distribution in the nightglow: Some model expectations. Planet. Space Sci., 39, 10491057, doi: 10.1016/0032-0633(91)90112-N. [Link]

McDade, I. C., E. J. Llewellyn, D. P. Murtagh, and R. G. H. Greer, 1987: ETON 5: Simultaneous rocket measurements of the $\mathrm{OH}$ Meinel $\Delta v=2$ sequence and $(8,3)$ band emission profiles in the nightglow. Planet. Space Sci., 35, 1137-1147, doi: 10.1016/0032-0633(87)90020-1. [Link]

Meinel, A. B., 1950: Hydride Emission Bands in the Spectrum of the Night Sky. Astrophys. J., 111, 207.

Melo, S. M. L., R. P. Lowe, and H. Takahashi, 1999: The nocturnal behavior of the hydroxyl airglow at the equatorial and low latitudes as observed by WINDII: Comparison with ground-based measurements. J. Geophys. Res., 104, 24657-24665, doi: 10.1029/1999JA900291. [Link]

Mende, S. B., G. R. Swenson, S. P. Geller, R. A. Viereck, E. Murad, and C. P. Pike, 1993: Limb view spectrum of the Earth's airglow. J. Geophys. Res., 98, 1911719125, doi: 10.1029/93JA02282. [Link]

Mendillo, M., J. Baumgardner, D. Nottingham, J. Aarons, B. Reinisch, J. Scali, and M. Kelley, 1997: Investigations of thermospheric-ionospheric dynamics with 6300-Å images from the Arecibo Observatory. J. Geophys. Res., 102, 7331-7343, doi: 10.1029/96JA02786. [Link]

Nee, J. B. and D. H. Peng, 2008: Observations of OH airglow and lightning excitations from the FORMOSAT-2 satellite. Adv. Geosci., 21, 177-188.

Oberheide, J., M. E. Hagan, R. G. Roble, and D. Offermann, 2002: Sources of nonmigrating tides in the tropical middle atmosphere. J. Geophys. Res., 107, 4567, doi: 10.1029/2002JD002220. [Link] 
Rajesh, P. K., J. Y. Liu, C. Y. Chiang, A. B. Chen, W. S. Chen, H. T. Su, R. R. Hsu, C. H. Lin, M.-L. Hsu, J. H. Yee, and J. B. Nee, 2009: First results of the limb imaging of $630.0 \mathrm{~nm}$ airglow using FORMOSAT-2/Imager of Sprites and Upper Atmospheric Lightnings. J. Geophys. Res., 114, A10302, doi: 10.1029/2009JA014087. [Link]

Shiokawa, K., C. Ihara, Y. Otsuka, and T. Ogawa, 2003: Statistical study of nighttime medium-scale traveling ionospheric disturbances using midlatitude airglow images. J. Geophys. Res., 108, 1052, doi: 10.1029/20 02JA009491. [Link]

Swenson, G. R. and S. B. Mende, 1994: OH emission and gravity waves (including a breaking wave) in all-sky imagery from Bear Lake, UT. Geophys. Res. Lett., 21, 2239-2242, doi: 10.1029/94GL02112. [Link]

Takahashi, H., Y. Sahai, B. R. Clemesha, D. M. Simonich, N. R. Teixeira, R. M. Lobo, and A. Eras, 1989: Equatorial mesospheric and $F$-region airglow emissions observed from latitude 40 south. Planet. Space Sci., 37, 649-655, doi: 10.1016/0032-0633(89)90035-4. [Link]

Takahashi, H., B. R. Clemesha, Y. Sahai, P. P. Batista, and D. M. Simonich, 1992: Seasonal variations of mesospheric hydrogen and ozone concentrations derived from ground-based airglow and lidar observations. J. Geophys. Res., 97, 5987-5993, doi: 10.1029/91JD03015. [Link]

Takahashi, H., R. A. Buriti, D. Gobbi, and P. P. Batista, 2002: Equatorial planetary wave signatures observed in mesospheric airglow emissions. J. Atmos. Sol.-Terr. Phys., 64, 1263-1272, doi: 10.1016/S1364-6826(02)00
040-8. [Link]

Taylor, M. J., W. R. Pendleton, Jr., S. Clark, H. Takahashi, D. Gobbi, and R. A. Goldberg, 1997: Image measurements of short-period gravity waves at equatorial latitudes. J. Geophys. Res., 102, 26283-26299, doi: 10.10 29/96JD03515. [Link]

Thayaparan, T., W. K. Hocking, and J. MacDougall, 1997: Amplitude, phase, and period variations of the quasi 2-day wave in the mesosphere and lower thermosphere over London, Canada $\left(43^{\circ} \mathrm{N}, 81^{\circ} \mathrm{W}\right)$, during 1993 and 1994. J. Geophys. Res., 102, 9461-9478, doi: 10.1029/96JD03869. [Link]

Ward, W. E., D. Y. Wang, B. H. Solheim, and G. G. Shepherd., 1996: Observations of the two-day wave in WINDII data during January, 1993. Geophys. Res. Lett., 23, 2923-2926, doi: 10.1029/96GL02897. [Link]

Yee, J. H., G. Crowley, R. G. Roble, W. R. Skinner, M. D. Burrage, and P. B. Hays., 1997: Global simulations and observations of $\mathrm{O}\left({ }^{1} \mathrm{~S}\right), \mathrm{O}_{2}\left({ }^{1} \Sigma\right)$ and $\mathrm{OH}$ mesospheric nightglow emissions. J. Geophys. Res., 102, 1994919968, doi: 10.1029/96JA01833. [Link]

Zhang, S. P. and G. G. Shepherd, 1999: The influence of the diurnal tide on the $\mathrm{O}\left({ }^{1} \mathrm{~S}\right)$ and $\mathrm{OH}$ emission rates observed by WINDII on UARS. Geophys. Res. Lett., 26, 529-532, doi: 10.1029/1999GL900033. [Link]

Zhang, S. P., R. G. Roble, and G. G. Shepherd, 2001: Tidal influence on the oxygen and hydroxyl nightglows: Wind Imaging Interferometer observations and thermosphere/ionosphere/mesosphere electrodynamics general circulation model. J. Geophys. Res., 106, 2138121393, doi: 10.1029/2000JA000363. [Link] 